\title{
A Study of Nitrogen Dynamics in an Integrated Stellate Sturgeon and Spinach Aquaponic System with Different Crop Densities
}

\author{
Stefan M. PETREA*1), Victor CRISTEA ${ }^{1)}$, Lorena DEDIU ${ }^{1)}$, Feng LIU ${ }^{2)}$, Maria CONTOMAN ${ }^{1)}$, Paul LUPOAE $^{3)}$ \\ Alina ANTACHE ${ }^{1)}$, Alexandru C. BANDI ${ }^{1)}$ \\ 1) "Dunărea de Jos" University of Galati, Faculty of Food Science and Engineering-Aquaculture, \\ Environmental Science and Cadastre Department, 47 Domnească Street, 800008 Galati, Romania \\ ${ }^{2)}$ China Agricultural University, PR China \\ ${ }^{3)}$ Natural Sciences Museum Complex Galaţi, Botanical Garden, 6A Street Regiment 11 Siret, Romania \\ *Corresponding author, email: stefan.petrea@ugal.ro
}

Bulletin UASVM Animal Science and Biotechnologies 71(2) / 2014,

Print ISSN 1843-5262; Electronic ISSN 1843-536X

DOI:10.15835/buasvmcn-asb:10586

\begin{abstract}
Obtaining and maintaining a healthy, productive aquaponic system requires intensive scientific research, monitoring and also adjustments, when necessary. To quantify the nitrogen budget for a stellate sturgeon -spinach integrated LECA grow bed aquaponic system, where three plants densities were used. The experiment was made in triplicate, using a 12 aquaponic units LECA grow bed aquaponic system. Three crops densities were used (V159 crops $/ \mathrm{m}^{2}, \mathrm{~V} 2-48 \mathrm{crops} / \mathrm{m}^{2}$ and V3- 39crops $/ \mathrm{m}^{2}$ and V4-no crops, only with LECA grow bed). Fish were were fed with $41 \%$ brute protein feed, at an average feeding ratio of $1.75 \%$ of total biomass. Water samples were taken and analysed by using photometric methods (Merck kits). The stellate sturgeon meat, spinach and also faeces nitrogen content was determined by Kjeldahl method. Differences between the removal rates for each of the three variants of tested crops densities were significant higher $(\mathrm{p}<0.05)$ at $\mathrm{V} 1$ compared to V3 and also higher at all three variants comparing them to the control variant. The amount of ammonium removal rates from biofilter and LECA grow bed was significant $(\mathrm{p}<0.05)$. Also, differences between spinach nitrogen composition from V3 compared to V1 were found significant higher $(\mathrm{p}<0.05)$. The nitrogen content from fish meat and fish faeces was found to be within normal limits, appear also in the literature. Considering the nitrite and nitrate concentrations, only spinach grown in aquaponic conditions, as presented above, at densities of $59 \mathrm{crops} / \mathrm{m}^{2}$, is marketable. In addition, it can be concluded that spinach growth in LECA grow bed aquaponic systems have a higher nitrogen content, comparing with the one growth using floating rafts technique.
\end{abstract}

Keywords: integrated aquaponics, nitrogen, removal rates, spinach, stellate sturgeon

\section{INTRODUCTION}

The aquaponics concept implies nutrients balance within a given integrated system (Petrea et al., 2013 A). Nitrogen is the most frequently limiting macronutrient for plants growth in aquaponic conditions. The evolution differences of nitrogen concentrations, in integrated aquaponic systems, are due to relative proportions of available nitrogen generated by fish and absorbed by plants (Petrea et al., $2013 \mathrm{~A}$ ). Also, the applied aquaponic growth techniques significantly influence the nitrogen balance in a recirculating integrated system.
The choice of aquaponic growing technique applied within a recirculating integrated system can be based on the independent advantages conferred by each hydroponic component. Thus, many researchers had made different studies on integrated aquaponic systems, by using generally sand, gravel or aggregate culture beds (Wilson et al., 2006; Mc.Murtry et al., 1993; Rafiee and Saad, 2006). Generally sand and gravel substrate systems may remove the requirementfor a separate biofilter or help the existing one, as the substrate also acts as a media for nitrifying bacteria growth and 
development, therefore replacing or improving the activity of conventional existing biofilters (Wilson et al., 2006). Also, sand and gravel substrates may also act as a solid filtering media (Mc.Murtry et al., 1997). The original concept of using the trickling filters surface to grow plants was established by aquaponic producers (Rakocy and Hargreaves, 1993; Timmons et al., 2002), which achieved remarkable fish to plant production ratios in market-scale production systems. Rafiee and Saad (2006) evaluated the effective use of natural zeolite as a bed growth medium for lettuce, in an integrated aquaponic system, along red tilapia. Its results demonstrated that zeolite, used as plant growth medium, could improve the environmental conditions for growing lettuce due to a better access of nutrients, because of the improvement in water nutrients composition (Rafiee and Saad, 2006). Rakocy and Nair (1987) mentioned that gravel media react with acids produced during nitrification and supply calcium for plant growth.

LECA is a type of clay, which is super-fired to create a porous medium that serves as a support for nitrifying bacteria. It is heavy enough to provide secure support for the plants root systems and was used in indoor and outdoor hydroponic systems (Lekang, 1999).

The main aim of present research is to quantify the nitrogen budget for an integrated stellate sturgeon (A. stellatus) -spinach (Spinacia oleracea) aquaponic system, where three crops

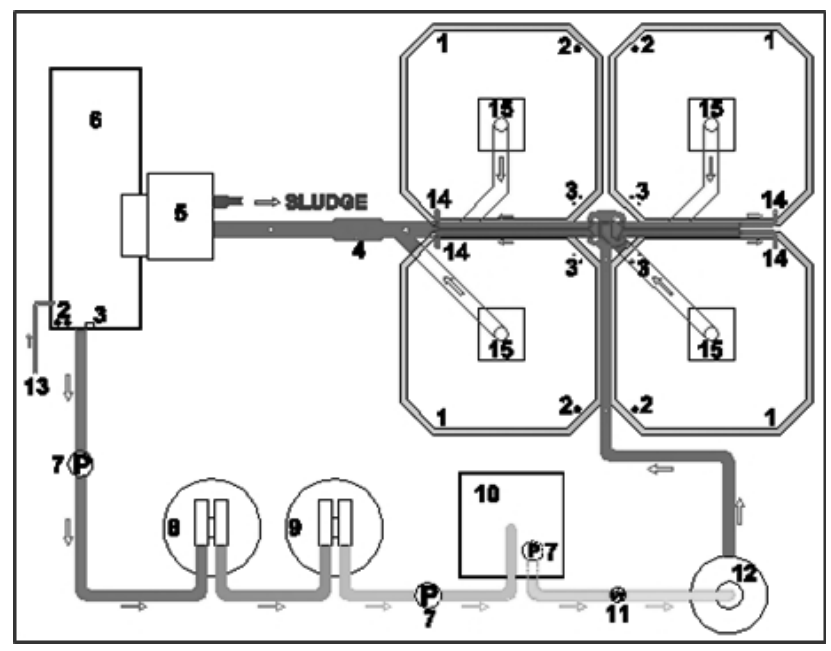

Fig. 1. The configuration and emplacement of main pilot recirculating system station (Petrea et al., 2014) growth densities were used. The second objective is to evaluate the influence of LECA growth media in terms of water treatment capacity and nitrogen absortion influence on crops.

\section{MATERIALS AND METHODS}

Integrated aquaponic system description. The present experiment took place between $20^{\text {th }}$ February and $4^{\text {th }}$ April 2013 at the main pilot recirculating system station of Aquaculture, Environmental Science and Engineering Department from Food Science Faculty -"Dunarea de Jos" University of Galati. The configuration of the pilot recirculating main system was sized according to specific technology described by Cristea (2008). The new emplacement of the recirculating main pilot station was described also by Petrea et al. (2014), as follows: 4 octagonal shape rearing units with a volume of approx. $2 \mathrm{~m} 3 /$ unit -No.1, with water level sensors-No.3 and nitrogen compounds sensors-No.2; RAS monk-No.4; mechanical drum filter-No.5; sump-No.6; sand filter-No.8; ACLM 05-ROMET Buzau type activated charcoal filter $(10 \mathrm{~m} 3 / \mathrm{h}$ maximum filtering speed) No.9; biological trickling filtration unit -No.10; sterilization UV filter (wavelength: $254 \mathrm{~nm}$ ) No.11; 3 pumps -No.7; oxygenation unit -No.12; growing units water outlet installation -No.15; growing units water inlet installation -No.14 and also automatically fresh water inlet-No.13 (Fig.1). According to Petrea et al. (2014), the aquaponic
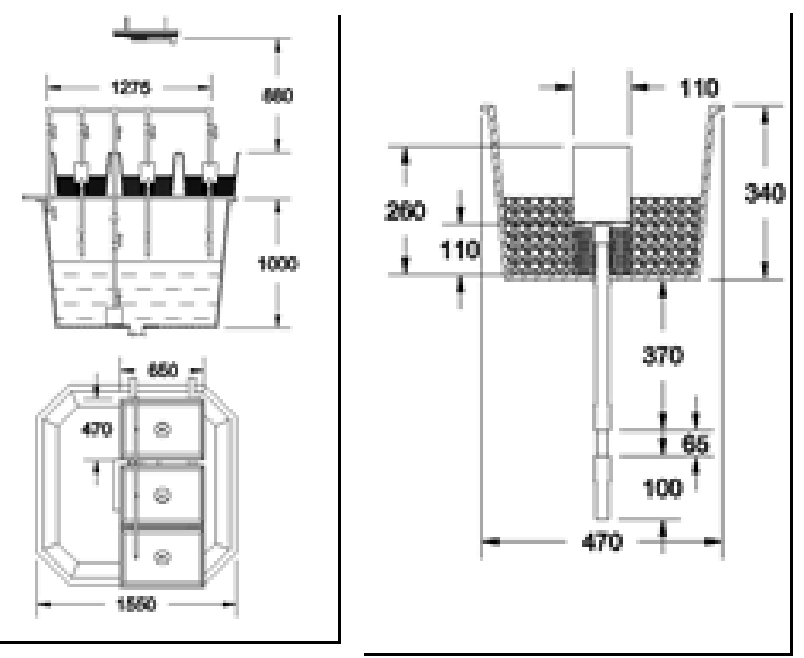

Fig. 2. A. longitudinal section of aquaponic modules; B. Top view of aquaponic modules; C. Crossing section of aquaponic modules (Petrea et al., 2014) 
modules consist in 12 rectangular plastic made units $(650 \times 470 \times 340 \mathrm{~mm})$, placed high above the fish growing units, on a special metal support (Fig. 2B). All 12 aquaponic modules were used in present research.

Each fish-growing unit corresponds with 3 aquaponic modules and inside the growing unit, a 2000L/h Hailea type pumps is placed in a protective casing made of mesh and steel frame, ensuring water recirculation from fish tank to hydroponic units and back (Fig. 2A.). The outlet of each hydroponic unit is placed in the middle of each one bottom (Fig. 2C.) (Petrea et al., 2014).

The aquaponic modules consist in 12 rectangular plastic made units $(650 \times 470 \times 340 \mathrm{~mm})$, placed high above the fish growing units, on a special metal support (Fig. 2B) (Petrea et al., 2014). Each growing unit corresponds with 3 aquaponic modules and inside the growing unit, a $2000 \mathrm{~L} / \mathrm{h}$ Hailea type pumps is placed in a protective casing made of mesh and steel frame, ensuring water recirculation from fish tank to hydroponic units and back (Petrea et al., 2014). Over the hydroponic units level, the inlet installation splits in 4 parts, 3 of them for each hydroponic unit and one that goes again directly into growing units and gives the possibility of controlling the inlet flow, without negative effect to the pump (Fig. 2A) (Petrea et al., 2014). The outlet of each hydroponic unit is placed in the middle of each one bottom and is ensure by a $25 \mathrm{~mm}$ PVC pipe, with a bigger diameter $(32 \mathrm{~mm})$ on the entrance and a diameter narrowing $(20 \mathrm{~mm})$ length of $65 \mathrm{~mm}$, placed $370 \mathrm{~mm}$ down the bottom of the unit (Fig. 2C.) (Petrea et al., 2014). The electric panel for the aquaponic modules ensures four Hailea type pumps $(2000 \mathrm{~L} / \mathrm{h}$ each) and four Metal - Halide lamps (600W each), with a total luminous power of $5800 \mathrm{~lm}$, placed above the hydroponic units. Each lamp has its own electronic droser (Petrea et al., 2014). All those described constructive characteristics ensure the following hydraulic parameters values: $21.82 \mathrm{~m} /$ day for hydraulic loading rate and $0.25 \mathrm{~h}$ for hydraulic retention time.

Experimental design. Before starting the experiment, the activation of biological trickling filtration unit was made as described by Dediu et al. (2012). Daily ammonia, nitrite and nitrate levels were monitored to determine the degree of ammonia oxidation to nitrate and therefore to observe when a stable state of bacterial biomass is obtained (Petrea et al. 2013 A.). For the 44 days experiment, a total number of 184 stellate sturgeons (A. stellatus), with an average initial weight of 169.75 grams, was used in parallel with 25 days old spinach (Spinacia oleracea). Fish were divided in 4 groups and were fed with Clasic Extra $1 \mathrm{P}$, at the folowing feeding ratios: G1-2.21\%; G21.85\%; G3-1.64\%; G4-1.28\%. Spinach was placed in the hydroponic units with the following stocking densities: (V1-59crops $/ \mathrm{m}^{2}-12$ crops/aquaponic unit, V2-48crops $/ \mathrm{m}^{2}-10$ crops/aquaponic unit, V3-39crops $/ \mathrm{m}^{2}$ - 8crops/aquaponic unit, V4control variant with no crops, only LECA growth media). The experiment was done in triplicate as follows: V1 (B1H1, B1H2, B1H3), V2 (B2H1, B2H2, B2H3), V3 (B3H1, B3H2, B3H3) and V4 (B4H1, B4H2, B4H3). The seedlings were obtained at Natural Sciences Museum Complex Galaţi Botanical Garden. The growth support media of spinach, cultivated in the aquaponic system, consisted of hydroton medium (LECA).

Water analysis. A daily percentage of $10 \%$ water exchange was applied. The technological water was analyzed in terms of temperature, $\mathrm{pH}$, dissolved oxygen, nitrates, nitrites and ammonium concentration. The temperature and dissolved oxygen were monitored with a portable WTW ProfiLine Oxi 3205 Dissolved Oxygen Meter. The pH was measured with WTW inoLab Multi 720 SET $\mathrm{pH} /$ Cond/Oxygen Meter and nitrogen compounds were determined by using Spectroquant Nova 400 spectrophotometer, with Merk compatible kits twice a week. Samples of water were taken from the outlet of the mechanical filter (inlet of biological filter), outlet of biological filter, each fish rearing unit (inlet of hydroponic units) and outlet of each hydroponic unit. The luminous intensity was measured with TESTO 545 light meter. The SGR and FCR fish production indicators were determined by using the formulas described by Ridha and Cruz (2001): Specific growth rate (SGR) [(ln mean final weight-ln mean initial weight) $\mathrm{x} 100]$ /culture days, (\%BW/day); feed conversion ratio $(\mathrm{FCR})=$ total weight of dry feed given/total wet weight gain $(\mathrm{g} / \mathrm{g})$. According to Petrea et al. (2013 A.), the nitrification performance of a biofilter is usually reported in literature as specific surface TAN removal or volumetric TAN removal rate. Thus, in present research nitrification rate has been calculated in terms of Volumetric TAN Removal (VTR), using the equation (Díaz et al., 
2012): VTR=[([NH $\left.{ }_{4}^{+}-\mathrm{N}\right]$ in $-\left[\mathrm{NH}_{4}^{+}-\mathrm{N}\right]$ out $\left.) \cdot \mathrm{Q}\right] /$ Vmedia, where VTR=amount of TAN removed per $\mathrm{m}^{3}$ of filter media per day; [NH4 $\left.4^{+}-\mathrm{N}\right]$ in and [NH4-N] out=ammonia concentration measured at the inlet and the outlet of the trickling filters system $\left(\mathrm{g} / \mathrm{m}^{3}\right) ; \mathrm{Q}=$ flow rate through the filters $\left(\mathrm{m}^{3} /\right.$ day $)$ and Vmedia is the volume of the filter media $\left(\mathrm{m}^{3}\right)$. The TAN removal rate in hyroponic units was calculated with the following formula (Dediu et al., 2012): TAN retained $\left(\mathrm{g} / \mathrm{m}^{2} /\right.$ day $)=\left(\left(\mathrm{Q} / \mathrm{V}^{*}\left(\mathrm{C}_{\text {in }}-\mathrm{C}_{\text {out }}\right)\right.\right.$ $\left.-\mathrm{dC}_{\text {out }} / \mathrm{d}_{\mathrm{t}}\right)^{*} \mathrm{~d}$, where, $\mathrm{Q}=$ the flow rate $\left(\mathrm{m}^{3} /\right.$ day $)$, $\mathrm{V}=$ system volume $\left(\mathrm{m}^{3}\right), \mathrm{C}=$ concentration of TAN $\left(\mathrm{g} / \mathrm{m}^{3}\right), \mathrm{d}=$ depth $(\mathrm{m}), \mathrm{t}=$ time $(\mathrm{d})$. The obtained results were then expresed in $\mathrm{m}^{2}$, by relating them to each aquaponic module growth surface. The biochemical determination of nitrogen content from spinach dry matter (leaf and root), fresh stellate sturgeon meat, fish feed and dry fish faeces was made by using Kjeldahl method (HACH, Cat. No. 23130-18 Instruction Manual). Faeces collection was made with a special EHEIM water vacuum cleaner with a mesh compartment for vacuum collection.

Statistical methods. Statistical analysis was performed using the IBM SPSS Statistics 20 for Windows. Statistical differences between treatments were tested using T test $(\alpha=0.05)$ after a normality test (Kolmogorov-Smirnov). Comparisons between variants were assessed using post-hoc Duncan test for multiple comparisons (ANOVA).

\section{RESULTS AND DISCUSSION}

Fish and plants growth performance. The total fish experimental biomass registered good growth performance, similar to those reported by other authors for stellate sturgeon growth in classic recirculated systems (Dicu et al., 2013) (Tab. 1).

Regarding spinach growth, better results were recorded in V3 experimental variant, where the lowest stocking density was used (Tab. 2). The differences between the variants, in term of spinach growth performance, are significant $(\mathrm{p}<0.05)$ and also, more prominent comparing with similar studies (Petrea et al., 2013 A, 2013 B).

The total nitrogen input quantity. A total quantity of $30661.2 \mathrm{~g}$ of Classic Extra $1 \mathrm{P}$ brute protein feed was distributed in the integrated system among the experimental period. The biochemical analysis of feed was made and as a result, a content of $42.1 \%$ brute protein was found. This means a total nitrogen input of $2065.3 \mathrm{~g}$, with a daily average of $46.93 \mathrm{~g} /$ day.

The evolution of water dissolved oxygen (DO), temperature, $\mathrm{pH}$, ammonium, nitrite and nitrate nitrogen. Temperature had a small downward evolution in the first half of the experimental period, followed byalarge fluctuation and then it continues it's relatively constant evolution until the end (Fig. 3). Thus, an average value of $19.64 \pm 1.21^{\circ} \mathrm{C}$ was registered for the outlet of $\mathrm{V} 1-\mathrm{B} 1 \mathrm{H}$ experimental variant; $19.48 \pm 1.23^{\circ} \mathrm{C}$ at

Tab. 1. The growth performance indicators for total fish experimental biomass (mean \pm S.E.)

\begin{tabular}{lc}
\hline Growth indicator & Value \\
\hline Total initial biomass $(\mathrm{g})$ & $31233 \pm 11.67$ \\
\hline Individual initial biomass $(\mathrm{g})$ & $169.74 \pm 0.25$ \\
\hline Total final biomass $(\mathrm{g})$ & $45682 \pm 455.61$ \\
\hline Individual final biomass $(\mathrm{g})$ & $248.27 \pm 9.9$ \\
\hline Total weight gain $(\mathrm{g})$ & $14449 \pm 465.01$ \\
\hline Individual weight gain $(\mathrm{g})$ & $78.53 \pm 10.1$ \\
\hline Average feed conversion ratio $(\mathrm{g} / \mathrm{g})$ & $1.77 \pm 0.36$ \\
\hline Average specific growth rate $(\% \mathrm{BW} /$ day) & $0.95 \pm 0.1$ \\
\hline
\end{tabular}

Tab. 2. Plant growth performance indicators for V1, V2 and V3 experimental variants (mean \pm S.E.)

\begin{tabular}{lccc}
\hline Plant growth indicator & $\begin{array}{c}\mathrm{V} 1-\mathrm{B} 1 \mathrm{H} \\
\left(59 \mathrm{crops} / \mathrm{m}^{2}\right)\end{array}$ & $\begin{array}{c}\mathrm{V} 2-\mathrm{B} 2 \mathrm{H} \\
\left(48 \mathrm{crops} / \mathrm{m}^{2}\right)\end{array}$ & $\begin{array}{c}\mathrm{V} 3-\mathrm{B} 3 \mathrm{H} \\
\left(39 \mathrm{crops} / \mathrm{m}^{2}\right)\end{array}$ \\
\hline Total initial biomass $(\mathrm{g})$ & $28.46 \pm 0.17$ & $20.95 \pm 0.23$ & $16.46 \pm 0.09$ \\
\hline Total final biomass $(\mathrm{g})$ & $460.29 \pm 2.86$ & $531.17 \pm 2.51$ & $617.25 \pm 2.34$ \\
\hline Individual weight gain $(\mathrm{g})$ & $11.2 \pm 2.99$ & $17.01 \pm 2.47$ & $25.03 \pm 2.81$ \\
\hline
\end{tabular}




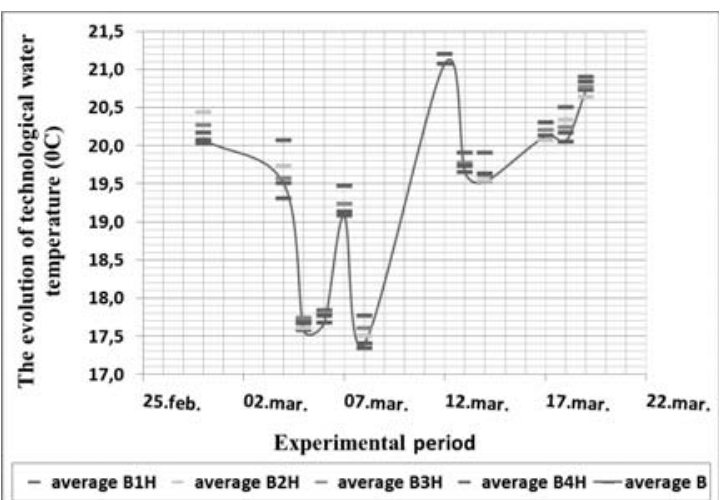

Fig. 3. The evolution of the technological water temperature

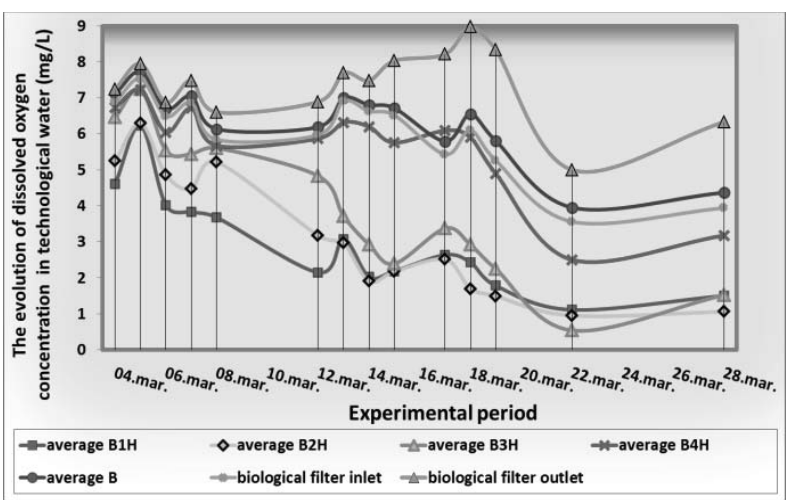

Fig. 5. The evolution of the technological water DO concentration.

V2-B2H; $19.5 \pm 1.2^{\circ} \mathrm{C}$ corresponding to $\mathrm{V} 3-\mathrm{B} 3 \mathrm{H}$ and $19.43 \pm 1.25^{\circ} \mathrm{C}$ for $\mathrm{V} 4-\mathrm{B} 4 \mathrm{H}$. The average value of water temperature at the inlet of all aquaponic modules (B) was $19.37 \pm 1.23^{\circ} \mathrm{C}$. No statistically significant differences were found between the experimental variants $(p>0.05)$. The evolution of $\mathrm{pH}$ registered a downward trend, most probably as a direct result of nitrifying bacteria activity (Fig. 4). The $\mathrm{pH}$ on the outlet of the aquaponic modules registered values within $7.28-7.82 \mathrm{upH}$, as follows: $7.49 \pm 0.17 \mathrm{upH}$ the average value for V1-BH1; 7.51 $\pm 0.17 \mathrm{upH}$ at V2-BH2; $7.52 \pm 0.18 \mathrm{upH}$ in case of V3-BH3 and 7.45 $\pm 0.17 \mathrm{upH}$ at V4-BH4 (control variant - only with LECA, no plants). The average value of $\mathrm{pH}$ at the inlet of the aquaponic units (B) was $7.55 \pm 0.16 \mathrm{upH}$. Differences were statistically significant only in case of $\mathrm{V} 4-\mathrm{BH} 4$ $(\mathrm{p}<0.05)$, comparing with the inlet value and with all other three outlet values.

Downward trend was also seen related to DO evolution (Fig. 5). This fact can be related in the first part of the experimental period, most

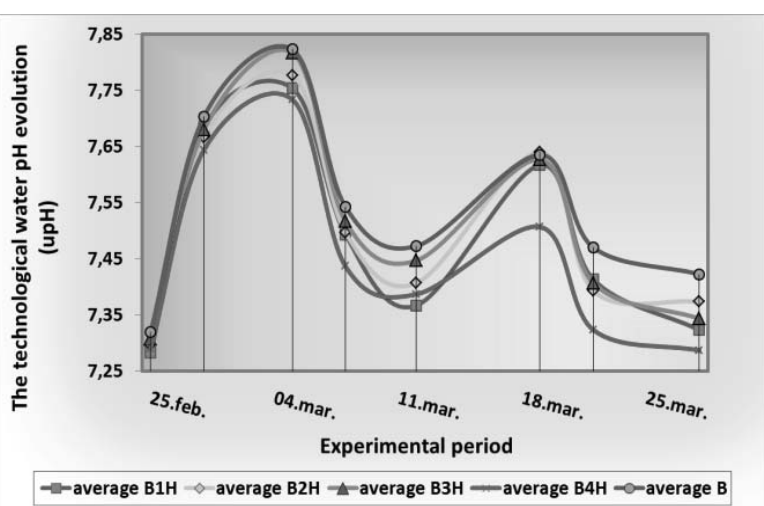

Fig. 4. The evolution of the technological water $\mathrm{pH}$

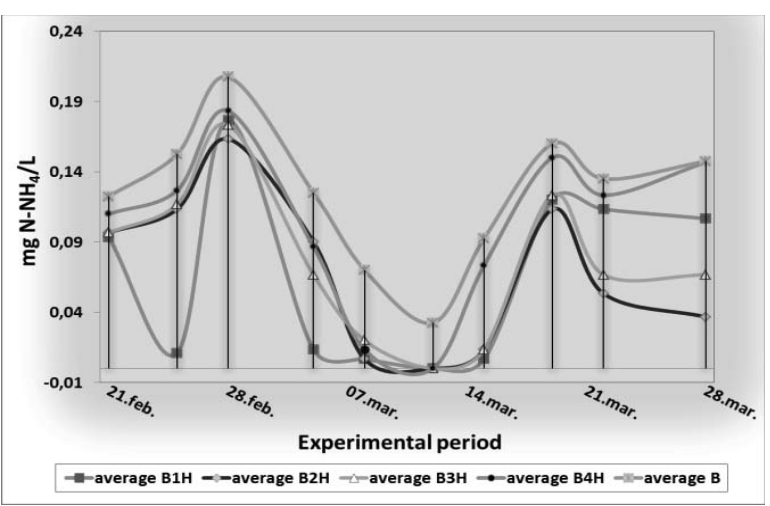

Fig. 6. The evolution of the technological water $\mathrm{N}-\mathrm{NH}_{4}$ concentration.

probably, with the activity of nitrifying bacteria, followed by the presence and also decomposition process of organic matter inside the LECA growth media, fact revealed by the evolution recorded on the last 8 experimental days (Fig. 5). Low concentrations of DO were recorded at the outlet of aquaponic modules, comparing with the inlet: $2.95 \pm 1.39 \mathrm{mg} / \mathrm{L}$ for V1-B1H outlet; $3.14 \pm 1.45 \mathrm{mg} / \mathrm{L}$ at $\mathrm{V} 2-\mathrm{BH} 2 ; 3.91 \pm 1.77 \mathrm{mg} / \mathrm{L}$ for V3BH3, $5.65 \pm 1.31 \mathrm{mg} / \mathrm{L}$ in case of control variant V4BH4 and $6.28 \pm 1.07 \mathrm{mg} / \mathrm{L}$ for fish rearing units B. Statistically significant difference were recorded comparing the group of first three experimental variants (V1, V2, V3) with the group formed by control variant and $B$ variant $(\mathrm{p}<0.05)$. For the evolution of $\mathrm{N}-\mathrm{NH}_{4}$ among the experimental period, it can be concluded, related also to $\mathrm{pH}$ and DO, that an intensive nitrification process made its presence observed in the first 25 experimental days, given the downward trend recorded (Fig. 6). After this period, a slight slower upward trend of $\mathrm{N}-\mathrm{NH}_{4}$ is observed, the presence of heterotrofic 
bacteria inside the LECA growth media being a possible explanations (Fig. 6). Mean values of $\mathrm{N}-\mathrm{NH}_{4}$ concentration were as follows: $0.06 \mathrm{mg} / \mathrm{L}$ in case of V1-B1H; $0.07 \mathrm{mg} / \mathrm{L}$ both in case of V2-B2H and $\mathrm{V} 3-\mathrm{BH} 3$ and $0.1 \mathrm{mg} / \mathrm{L}$ for the control variant. The average value of $\mathrm{N}-\mathrm{NH}_{4}$ concentration from the fish rearing units (inlet of aquaponic modules -B) was $0.12 \mathrm{mg} / \mathrm{L}$. Statistically significant differences were recorded between $\mathrm{N}-\mathrm{NH}_{4}$ inlet and outlet concentrations, as well as in case of first three experimental variants, comparing with control variant $(\mathrm{p}<0.05)$.

The evolution of $\mathrm{N}-\mathrm{NO}_{2}$ concentration, at aquaponic modules level, becomes relatively constant after the first 8 experimental days, when some fluctuations were recorded (Fig. 7). Same evolution had been recorded also in case of trickling biological filter. This may be related with the adaptability capacity of nitrite-oxidizing bacteria presented in LECA growth media and also on trickling biological filter bactoballs. The following mean values for $\mathrm{N}-\mathrm{NO}_{2}$ concentration were recorded: $0.14 \pm 0.04 \mathrm{mg} / \mathrm{L}$ at $\mathrm{V} 1-\mathrm{BH} 1$ outlet; $0.12 \pm 0.04 \mathrm{mg} / \mathrm{L}$ at $\mathrm{V} 2-\mathrm{BH} 2 ; 0.14 \pm 0.3 \mathrm{mg} / \mathrm{L}$ for V3BH3; $0.15 \pm 0.04 \mathrm{mg} / \mathrm{L}$ in case of control variant (V4$\mathrm{BH} 4)$ and $0.1 \pm 0.03 \mathrm{mg} / \mathrm{L}$ at the inlet of aquaponic modules (B). Differences were statistically significant between the outlet $\mathrm{N}-\mathrm{NO}_{2}$ values and the inlet ones $(\mathrm{p}<0.05)$. Also, statistically significant differences were recorded between V2-BH2 and the rest of experimental variants $(p<0.05)$. Concentrations of $\mathrm{N}-\mathrm{NO}_{2}$ with an average value of $0.14 \pm 0.04 \mathrm{mg} / \mathrm{L}$ were recorded at the inlet of the biological trickling filter and $0.18 \mathrm{mg} / \mathrm{L} \pm 0.05$ at the outlet. For mechanical drum filter outlet, a mean $\mathrm{N}-\mathrm{NO}_{2}$ concentration of $0.13 \pm 0.04 \mathrm{mg} / \mathrm{L}$ was obtained. A quite various, non-constant, evolution

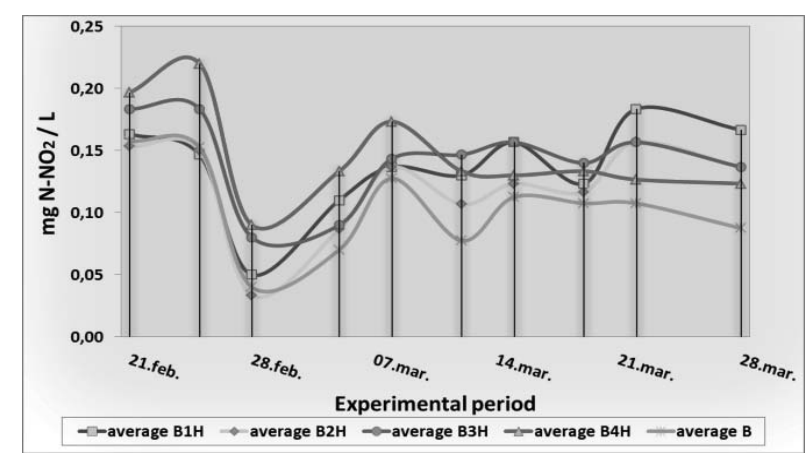

Fig. 7. The evolution of the technological water $\mathrm{N}-\mathrm{NO}_{2}$ concentration. was observed related with $\mathrm{N}-\mathrm{NO}_{3}$ concentration (Fig. 8). The alternation of upward and downward trend observed at the outlet of aquaponic modules can be related to both LECA growth media nitrification performance and nutritional requirements variations of spinach. Also, as other authors mentioned in similar studies (Petrea et al., 2013 A), quantity of feed administrated in certain periods can be a determinant factor. The nitrate nitrogen concentration registered the following mean values: $34.54 \pm 8.34 \mathrm{mg} / \mathrm{L}$ at V1-BH1 outlet; $35.5 \pm 8.85 \mathrm{mg} / \mathrm{L}$ for $\mathrm{V} 2-\mathrm{BH} 2 ; 36.58 \pm 8.83 \mathrm{mg} / \mathrm{L}$ in case of V3-BH3, $44.64 \pm 9.3 \mathrm{mg} / \mathrm{L}$ for control variant and $39.74 \pm 9.18 \mathrm{mg} / \mathrm{L}$ for the aquaponic inlet (B). Significant differences were recorded between the first three experimental variants and the control variant, as well as between the outlet and inlet from every variant $(\mathrm{p}<0.05)$. The nitrate nitrogen concentration was higher, comparing with similar studies (Petrea et al., 2013 A), most probably because of the tehnical particularities of the recirculated integrated system that was used (hydraulic loading rate, hydraulic retention time, the design of aquaponic modules), but also the amount of feed distributed during the experimental period and the reared fish species are two variables that must be taken into consideration during this comparative statement.

Water treatment capacity. Biofilters performances are crucial in aquaponics, especially in recirculating integrated systems. When it comes to the situation of evaluating biofilters performances, the two models encountered in the literature are related to evaluation of surface specific TAN removal rate and volumetric TAN removal rate (Díaz et al., 2012). In present study, volumetric TAN removal (VRT) was calculated, and values

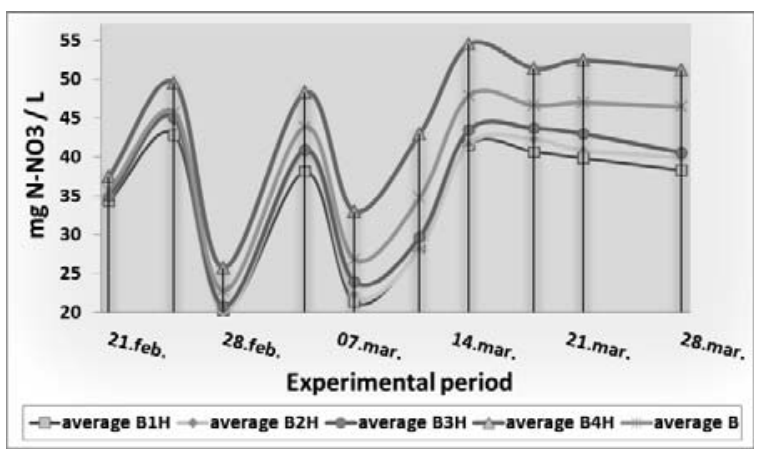

Fig. 8. The evolution of the technological water $\mathrm{N}-\mathrm{NO}_{3}$ concentration. 


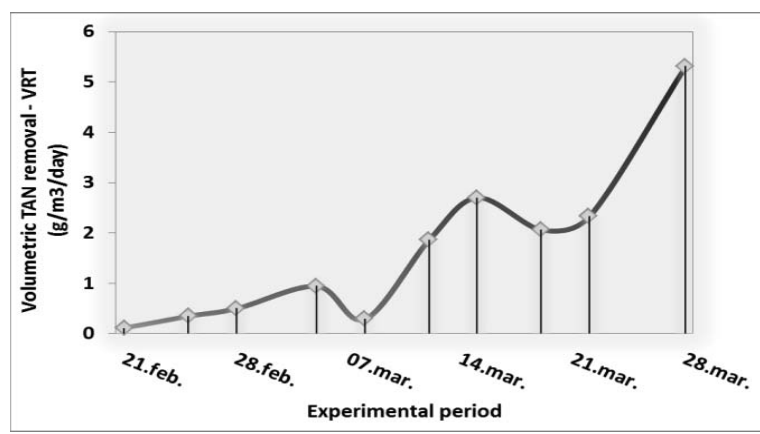

Fig. 9. The evolution of volumetric TAN removal (VRT)

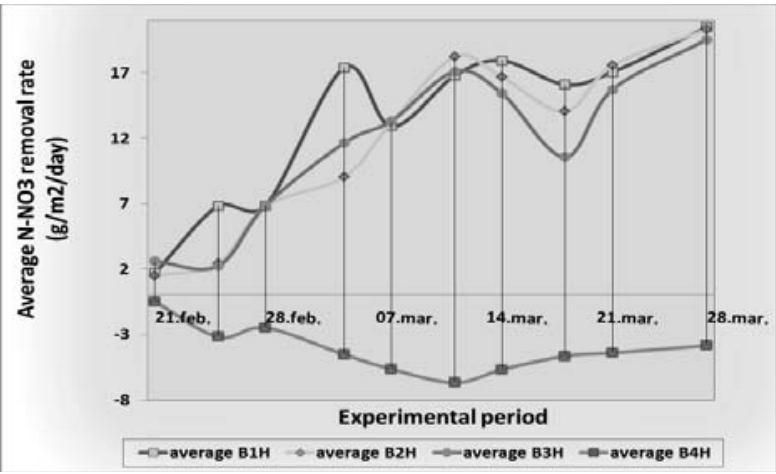

Fig. 11. The evolution of $\mathrm{N}-\mathrm{NO}_{3}$ removal rate

between $0.11-5.31 \mathrm{~g} / \mathrm{m}^{3} /$ day were recorded, with an average of $1.64 \mathrm{~g} / \mathrm{m}^{3} /$ day. The obtained values are higher comparing with previous studies (Petrea et al., 2013 A). The evolution of VRT has a more pronounced upward trend (Fig. 9), comparing with other similar studies (Petrea et al., $2013 \mathrm{~A})$. Also, the evolution of TAN removal rate has an upward trend, more gradual pronounced on the last 15 days of the experimental period in case of V2-BH2 and V3-BH3, comparing with the first experimental variant (Fig. 10). This might be the consequence of a lower competition between crops in terms of nutrients absorption, fact that offered them better condition for their physiological processes. The average TAN removal rate registered the following average values: 0.3 $\mathrm{g} / \mathrm{m}^{2} /$ day for V1-BH1; $0.37 \mathrm{~g} / \mathrm{m}^{2} /$ day for V2-BH2; $0.31 \mathrm{~g} / \mathrm{m}^{2} /$ day at $\mathrm{V} 3-\mathrm{BH} 3$ and $0.16 \mathrm{~g} / \mathrm{m}^{2} /$ day in case of control variant (V4-BH4). Values were better than those reported by Petrea et al. (2013 A), for an integrated recirculated system where a combination of rainbow trout-spinach was used, by applying floating rafts aquaponic technique. Differences between the first three experimental

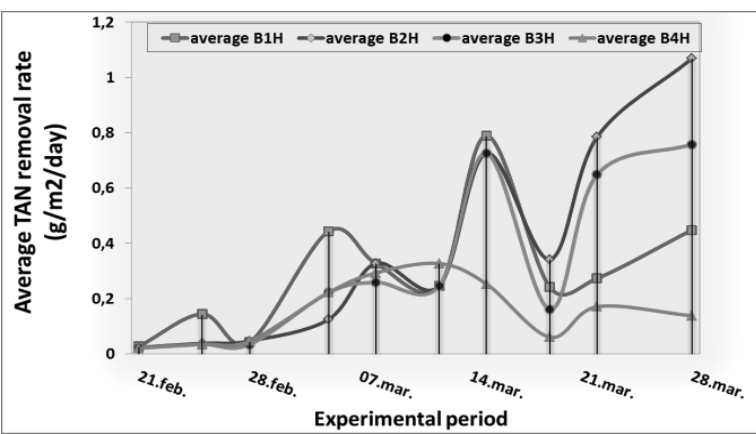

Fig. 10. The evolution of average TAN removal rate

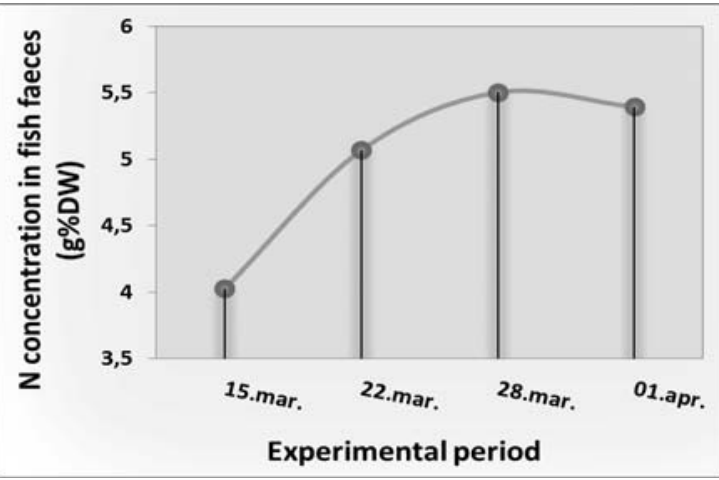

Fig. 12. The evolution of $\mathrm{N}$ concentration in stellate sturgeon faeces

variants and the control variant are statistically significant $(\mathrm{p}<0.05)$ in terms of TAN removal.

Regarding $\mathrm{N}-\mathrm{NO}_{3}$ removal rate, the following average values were registered: $13.4 \pm 6.16 \mathrm{~g} / \mathrm{m}^{2} /$ day at $\mathrm{V} 1-\mathrm{BH} 1 ; 11.97 \pm 6.7 \mathrm{~g} / \mathrm{m}^{2} /$ day for $\mathrm{V} 2-\mathrm{BH} 2$; $11.49 \pm 5.96 \mathrm{~g} / \mathrm{m}^{2} /$ day in case of $\mathrm{V} 3-\mathrm{BH} 3$ and a average value of $-4.17 \pm 1.78 \mathrm{~g} / \mathrm{m}^{2} /$ day for control variant. Values are better, comparing to the ones obtained by Petrea et al. (2013 A). In terms of evolution, the negative values obtain for control variant (Fig. 11) are not encountered in previous similar studies (Petrea et al., 2013 A) and they are generated by the nitrification process present at the LECA growth media level. The differences are statistically significant between V1-BH1 and the other experimental variants and also between first three experimental variants and control variant $(\mathrm{p}<0.05)$.

Nitrogen recovery by faeces, fish and plants biomass. The nitrogen concentration from stellate sturgeon faeces had an upward evolution (Fig. 12), with a average value of $4.99 \pm 0.67 \mathrm{~g} \%$ dry weight (DW). The obtained value is higher than the one reported by Petrea et al. (2013 A), who obtained 


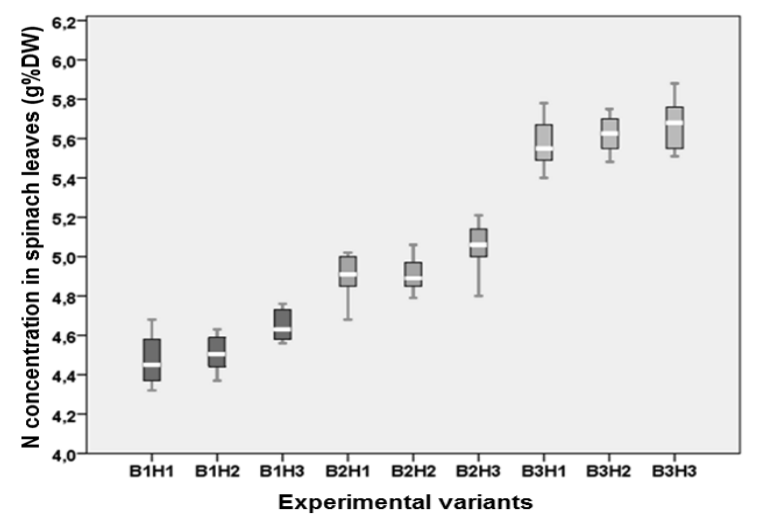

Fig. 13. $\mathrm{N}$ concentration in spinach leaves

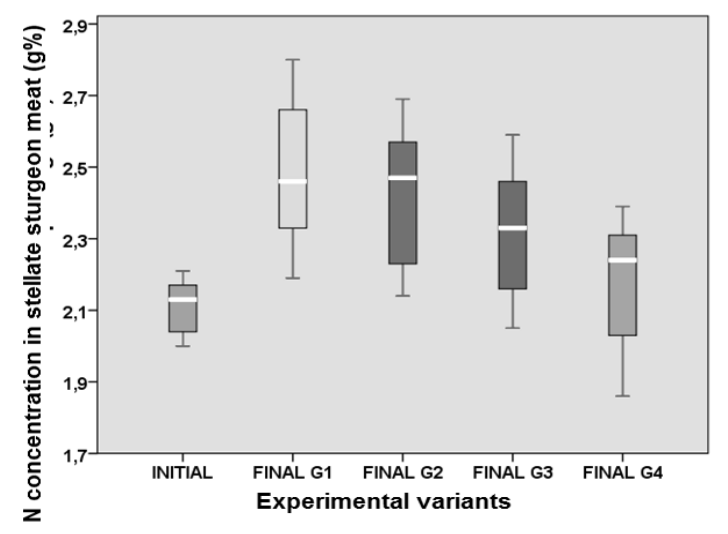

Fig. 15. $\mathrm{N}$ concentration in stellate sturgeon meat

a nitrogen concentration of $2.28 \mathrm{~g} \% \mathrm{DW}$ in case of rainbow trout faeces, that was reared in intensive conditions and fed with the same Clasic Extra $1 \mathrm{P}$. Regarding the nitrogen concentration from spinach leaves, an average value of $4.55 \pm 0.11 \mathrm{~g} \% \mathrm{DW}$ was registered at $\mathrm{V} 1 ; 4.95 \pm 0.13 \mathrm{~g} \% \mathrm{DW}$ at $\mathrm{V} 2$ and $5.63 \pm 0.13 \mathrm{~g} \% \mathrm{DW}$ in case of V3 (Fig. 13). Differences were statistically significant between first two variants and V3 experimental variant $(p<0.05)$. Also, nitrogen concentration from spinach roots registered the following average values: $8.52 \pm 0.13 \mathrm{~g} \% \mathrm{DW}$ was registered at $\mathrm{V} 1$; $9.66 \pm 0.17 \mathrm{~g} \% \mathrm{DW}$ at $\mathrm{V} 2$ and $11.01 \pm 0.37 \mathrm{~g} \% \mathrm{DW}$ in case of V3 (Fig. 14). Differences between all three variants are statistically significant $(p<0.05)$. Values were higher than those obtained by Petrea et al. (2013 A) for spinach growth in floating rafts aquaponic conditions by applying the same growth densities like in current study and using rainbow trout as fish species. It can be also concluded that nitrogen concentration registered in present study for leaves of spinach, growth in aquaponic

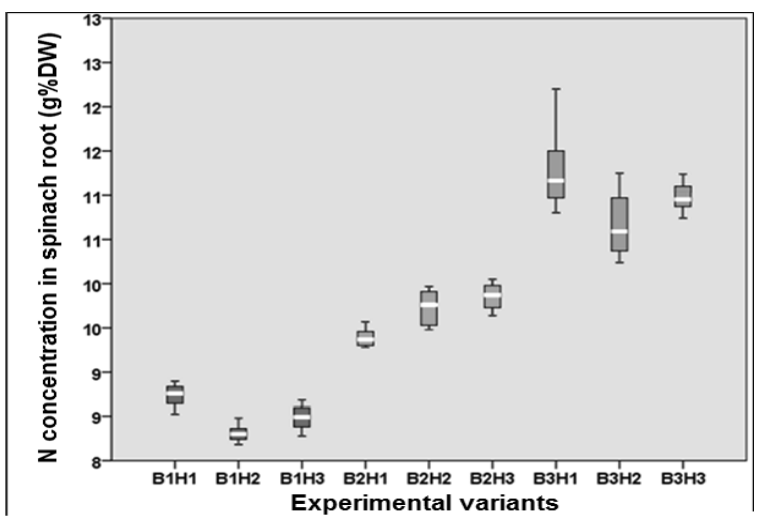

Fig. 14. N concentration in spinach roots

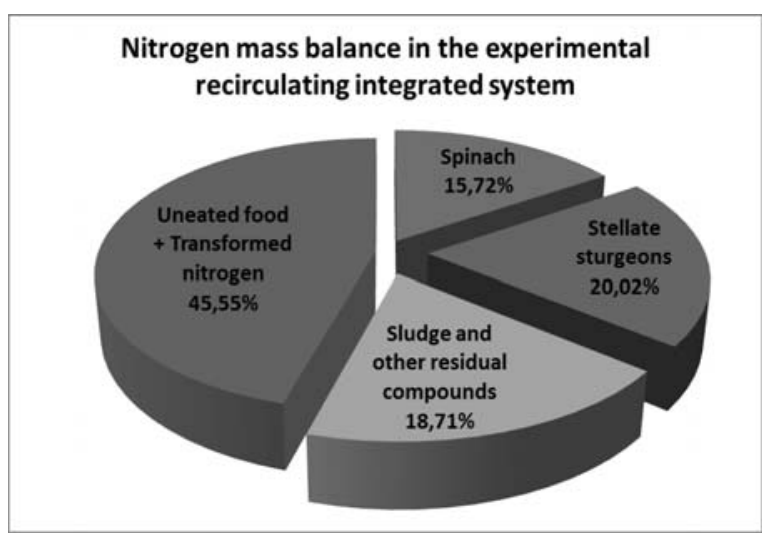

Fig. 16. Nitrogen mass balance in the integrated RAS

conditions by using substrate (LECA) technique, are over the concentrations of marketable spinach leaves, reported by Petrea et al. (2013 A).

The determination of nitrogen concentration from stellate sturgeon meat led to the following average values: $2.11 \pm 0.09 \mathrm{~g} \%$ for the initial biomass (before starting the experiment); $2.49 \pm 0.24 \mathrm{~g} \%$ for $\mathrm{G} 1,2.42 \pm 0.23 \mathrm{~g} \%$ in case of $\mathrm{G} 2$; $2.31 \pm 0.22$ at G3 and $2.17 \pm 0.21 \mathrm{~g} \%$ for G4 (Fig. 15). The difference between the initial concentration and the final concentration recorded for the first three experimental variants are statistically significant $(\mathrm{p}<0.05)$. Also, difference between the first two experimental variants and G4 are statistically significant $(\mathrm{p}<0.05)$.

By taking into consideration all the results obtained concerning the nitrogen concentration, a nitrogen mass balance was made, valid for current experimental recirculating integrated system, in (Fig. 16). The residual nitrogen that was not found on the integrated system studied areas was considered as being a apart of the sludge that was 
automatically eliminated at the level of drum filter on its auto-washed process or it was eliminated into the air as free nitrogen.

\section{CONCLUSION}

As conclusions of this study, it can be state that LECA growth media is efficient in using it for bioremediation purposes, fact revealed by the controlvariant, based on its registered TAN removal rate and by its negative values related to nitrate nitrogen removal rate. Also, V1 experimental variant registered the best performance in terms of water treatment, from all three tested variants. The nitrogen concentration from spinach roots and leaves are higher when using LECA media aquaponic technique, compared with floating rafts technique, used for similar studies in other previous publication. Regarding the obtained nitrogen mass balance, it must be stated that it reveals the phytoremediation capacity of spinach and also, it provides an overview related to water treatment and nitrogen use efficiency of the recirculating integrated system, that has been design for this experiment.

Acknowledgments. The work of Petrea Stefan Mihai and Antache Alina has been funded by the Sectoral Operational ProgrammeHuman Resources Development 2007-2013 of the Ministry of European Funds through the Financial Agreement POSDRU/159/1.5/S/132397 - ExcelDOC. The work of co-autor Paul Lupoae was supported by Project SOP HRD - PERFORM/159/1.5/S/138963.

\section{REFERENCES}

1. Cristea V (2008). Scientific partnerships to develop a pilot recirculating system for the promotion and implementation of innovative technologies for superintensive aquaculture, Granted by: Ministry of Education and Research, National Authority for Scientific Research, Program CEEX, Module I, AGRAL.

2. Díaz V, Ibánez R, Gómez, P, Urtiaga AM, Ortiz I (2012) Kinetics of nitrogen compounds in a commercial marine Recirculating Aquaculture System. Aquacultural Engineering, Model AQUE-1635: 20-27.

3. Dediu L, Cristea V, Zhang X (2012). Waste production and valorization in an integrated aquaponic system with bester and lettuce. African Journal of Biotechnology, 11(9): 2349-2358.

4. Dicu (Stroe) MD, Cristea V, Dediu L, Maereanu M, Petrea Şt $M$ (2013). The influence of feeding frequency on growth performance and meat quality of A. Stellatus (Pallas, 1771) species, growth in a recirculating aquaculture system. "Scientific Papers, Animal Science Series" Vol. 60. USAMV Iasi, Faculty of Animal Sciences: 193-198.

5. Lekang O (1999). Efficiency of nitrification in trickling filters using different filter media, Aquacultural Engin., 21: 181-199.

6. McMurtry MR, Sanders DC, Patterson RP, Nash A (1993). Yield of tomato irrigated with recirculating aquaculture water. J Prod Agric 6: 429-432.

7. McMurtry MR, Sanders DC, Cure JD, Hodson RG, Haning BC, St Amand PC (1997). Efficiency of water use of an integrated fish/vegetable co-culture system. J World Aquacult Soc 28: 420-428.

8. Petrea St M, Cristea V, Dediu L, Contoman M, Ion (Placinta) S, Mocanu (Cretu) M and Antache A (2013 A). Study of nitrogen cycle in an integrated aquaponic system with different plant densities; Bulletin of University of Agricultural Sciences and Veterinary Medicine ClujNapoca. Animal Science and Biotechnologies.

9. Petrea SM, Cristea V, Dediu L, Contoman M, Lupoae P, Mocanu (Cretu) M and Coada MT (2013 B). Vegetable production in an integrated aquaponic system with rainbow trout and spinach; Animal Science and Biotechnologies. Bulletin of University of Agricultural Sciences and Veterinary Medicine Cluj-Napoca.

10. Petrea S M, Cristea V, Dediu L, Contoman M, Lupoae P, Antache A, Dicu MD, Coada MT (2014). Vegetable production in an integrated aquaponic system with stellate sturgeon and spinach - Matador variety; Bioengineering of animal resources Symposium; Animal Science and Biotechnologies 47 (1): 235-245.

11. Ridha MT, Cruz EM (2001). Effect of biofilter media on water quality and biological performance of the Nile Tilapia (Oreochromis niloticus L) reared in a simple recirculation system. Aquacultural Engineering 24: 57166.

12. Rafiee Gh, Che Roos Saad (2006). The Effect of Natural Zeolite (Clinoptiolite) on Aquaponic Production of Red Tilapia (Oreochromis sp.) and Lettuce (Lactuca sativa var. longifolia), and Improvement of Water Quality; J. Agric. Sci. Technol. (2006) Vol. 8: 313-323.

13. Rakocy JE, Nair A (1987). Integrating Fish Culture and Vegetable Hydroponics: Problems and Prospects. Virgin Islands Perspectives, vol. 1. University of the Virgin Islands, Agricultural Experiment Station, St. Croix, U.S. Virgin Islands, 19-23.

14. Rakocy JE, Hargreaves JA (1993). Integration of vegetable hydroponics with fish culture: a review; Wang JK (ed) Techniques for modern aquaculture. American Society of Agricultural Engineers, St. Joseph Michigan USA, 112-136.

15. Timmons $\mathrm{M}$, Ebeling J, Wheaton F, Summerfelt $\mathrm{S}$ and Vinci B (2002). Recirculating Aquaculture Systems, Northeastern Regional Aquaculture Center, Cayuga Aqua Ventures, New York: 346, 769.

16. Wilson A, Lennard Ć, Brian V Leonard (2006). A comparison of three different hydroponic sub-systems (gravel bed, floating and nutrient film technique in an Aquaponic test system; Aquacult Int Springer Science, Business Media B.V. 14: 539-550. 